\title{
A biologia do conhecer de Maturana e algumas considerações aplicadas à educação
}

\author{
The Maturana biology of knowledge \\ and some considerations applied to education
}

\author{
Marcelo Naputano ${ }^{1}$ \\ https:// orcid.org/0000-0003-4895-579X \\ José Sterza Justo ${ }^{2}$ \\ https://orcid.org/0000-0002-5472-9900
}

\begin{abstract}
Resumo: Pretende-se considerar alguns elementos da teoria de Humberto Maturana, instituidor da Biologia do Conhecer, que parecem fundamentais para o desenvolvimento de uma epistemologia científica que possa colocar em evidência a possível superação ou tentativa de superação, da dicotomia entre a natureza e a cultura ou entre a biologia e a sociologia, considerando-se também suas implicações para a educação. Ou seja, são abordados alguns elementos relevantes da teoria de Maturana, descritos na obra Biologia do fenômeno social, e a possibilidade de sua aplicabilidade imediata na educação, consideradas na obra Uma abordagem da educação atual na perspectiva da biologia do conhecimento. Essas leituras são relevantes porque a teoria de Maturana reconsidera a importância da experiência como promotora de conhecimento e, desse modo, serão as possíveis considerações do concreto da educação a nos oferecer uma leitura mais aprofundada da teoria descrita. A conclusão trata de uma breve consideração pedagógica.
\end{abstract}

Palavras-chave: Humberto Maturana. Epistemologia. Biologia do conhecer. Educação.

\begin{abstract}
Our work considers some elements of the theory of Humberto Maturana, founder of Biology of Knowledge that we believe are essential for the development of a scientific epistemology that can provide evidence and possibly overcome, or attempt to overcome, the dichotomy nature/culture and biological/sociological approaches and also consider their implications for education. That means, some relevant elements of Maturana's theory described in the work Biology of social phenomena are approached, and the possibility of its immediate applicability in education considered in the work $A$ study of current biology education in the knowledge perspective. These readings are relevant because Maturana's theory redevelops the importance of experience as a promoter of knowledge and thus the development in education of concrete considerations to offer us a deeper reading of the described theory. We conclude with a brief pedagogical consideration.
\end{abstract}

Keywords: Humberto Maturana. Epistemology. Biology of knowledge. Education.

\footnotetext{
${ }^{1}$ Universidade Federal de Roraima (UFRR), Boa Vista, RR, Brasil. E-mail: <marcelo.naputano@ufrr.br>.

${ }^{2}$ Universidade Estadual Paulista (Unesp), Faculdade de Ciências e Letras, Departamento de Psicologia Evolutiva Social e Escolar, Assis, SP, Brasil.
} 


\section{Introdução}

Em nosso texto, pretendemos considerar alguns elementos da teoria de Humberto Maturana, instituidor da Biologia do Conhecer, que nos parecem fundamentais para o desenvolvimento de uma epistemologia científica que possa colocar em evidência a possível superação, ou tentativa de superação, entre a natureza e a cultura ou entre a biologia e a sociologia. Também consideraremos suas implicações para a educação. Ou seja, pretendemos avaliar as bases de sua teoria e a possibilidade de sua aplicabilidade subsequente na educação, porque é uma teoria que reconsidera a importância da experiência como promotora de conhecimento. Para tanto, iremos avaliar dois breves escritos de Humberto Maturana. O primeiro texto, Biología del fenómeno social, inserido na coletânea Desde la biología a la psicología, quarta edição chilena de 2006, com sua primeira publicação em 1985 na revista Delfin, de Stuttgart, com o título, em alemão, Biologie der sozialität. O segundo texto, Uma abordagem da educação atual na perspectiva da biologia do conhecimento, inserido na coletânea Emoçôes e linguagem na educação e na política, em sua primeira edição brasileira, publicado pela UFMG em 1998, sendo sua edição original publicada em espanhol em 1990, fruto de duas conferências de Maturana, em 1988, no Centro de Estudios del Desarrollo, em Santiago, no Chile.

Inicialmente, faz-se necessária uma pequena apresentação deste autor contemporâneo, nascido em Santiago do Chile, em 14 de setembro de 1928, que ainda trabalha e está em plena produção de suas obras e ideias. Deste modo, discorrer sobre Maturana oferece uma dificuldade que vai além de sua teoria, complexa por si mesma, pois esta é uma construção ainda em ato. Humberto Maturana, neurobiólogo e professor do Departamento de Biologia da Facultad de Ciencias da Universidad de Chile cofundou, com Ximena Dávila, a Escuela de Matriztica de Santiago, em 2000, onde também é docente. Estudou medicina na Universidad de Chile, biologia na University College of London e fez seu pós-doutorado na Harvard University. O interesse do instituto Matriztica, declarado em seu site na internet, coloca em evidência o desígnio da obra de Maturana, conjuntamente com seus colaboradores, que é o do desenvolvimento do ser humano denominado biológico-cultural, a fim de uma transformação cultural, educacional e organizacional (MATRIZTICA, 2015). Este objetivo declarado, da intenção de uma "metamorfose" no mundo, é um dos motivos da pertinência de nossa proposta de leitura de Maturana, por meio de dois textos distintos entre si, um com uma breve explicação de sua teoria de modo mais hermético e o outro de sua aplicabilidade imediata e de elocução mais acessível, afrontando argumentos de extrema relevância prática para nosso mundo atual, como o da educação - que nos interessa particularmente neste texto.

\section{Maturana e sua biologia do fenômeno social}

No prefácio de Emoções e linguagem na educação e na política, Aurora Rabelo (RABELO, 1998), socióloga que apresenta ao público brasileiro esta obra, parafraseando a afirmação de Michel Foucault, quando disse que o século XX seria o século de Gilles Deleuze, afirma que o século XXI seria de Humberto Maturana. Esta afirmação, polêmica e que nos parece prematura, pode encontrar facilmente dissenso nos meios acadêmicos, pois a obra de Maturana ainda está em movimento e o século ainda em seu início. Contudo, sem nenhuma dúvida, Rabelo coloca 
em evidência que se trata de um autor de grande relevância, principalmente pela sua tentativa de estabelecer uma continuidade entre o biológico e o social.

Este entusiasmo não é exagerado, ao constatarmos a declarada intenção de Maturana (2006) na introdução de Biología del fenómeno social quando afirma o modo pelo qual pretende analisar o dilema da compreensão dos seres humanos sociais e individuais ao mesmo tempo e, mais arraigado na história de longa duração, o dilema da nossa constituição humana, entre a natureza e a cultura, que, desde a Antiguidade, é uma problemática não fácil de solucionar.

Mi propósito en este pequeño artículo es analizar los fenómenos sociales de una manera no tradicional, y mostrar que de hecho y de una manera inevitable, el ser humano individual es social, y el ser humano social es individual. No haré esto, sin embargo, desde una argumentación filosófica, sociológica o psicológica. Lo haré con una argumentación biológica, es decir, mirando a los fundamentos mismos de nuestro ser seres vivos (MATURANA, 2006, p. 70).

A maneira não tradicional à qual se refere Maturana é a utilização da biologia como elemento fundamental para a conservação de nossa organização e adaptação, que se produz no mundo social e linguístico, ou seja, a partir de um pressuposto biológico da cognição humana, sem a utilização de argumentação filosófica, sociológica ou psicológica. Maturana constrói sua arguição em Biología del fenómeno social utilizando-se, sem explícita declaração, do que se encontra na sua outra obra objeto de nosso texto, a ideia da objetividade do observador - que será denominada como objetividade entre parênteses, noção que indica que não existe uma realidade independente do observador, em contraposição à objetividade sem parênteses, noção esta utilizada pelas ciências clássicas, segundo a qual os objetos existem independentemente do observador:

No outro caminho explicativo, que eu denomino de objetividade-entre-parênteses, como já disse, ao aceitar a pergunta pela origem de nossa capacidade de observar, a biologia adquire presença. Quer dizer, ao perguntarmos pela origem das capacidades cognitivas do observador, não podemos deixar de ver que estas se alteram ou desaparecem ao alterar-se nossa biologia, e que não podemos desprezar mais nossa condição de seres que na experiência não podem distinguir entre ilusão e percepção. Ademais, ao nos darmos conta disto, damo-nos conta, também, de que, quando escutamos uma proposição explicativa ou uma reformulação da experiência e a aceitamos como explicação, o que aceitamos não é uma referência a algo independente de nós, mas uma reformulação da experiência com elementos da experiência que satisfaça algum critério de coerência que nós mesmos propomos explícita ou implicitamente. Em outras palavras, nós nos damos conta também de que depende de nós aceitarmos ou não uma certa reformulação da experiência a ser explicada como explicação dela, segundo um critério de aceitação que temos em nosso escutar e, portanto, que a validade das explicações que aceitamos se configura em nossa aceitação e não independentemente dela. Interessante, não é? (MATURANA, 1998, p. 46-47, grifos do autor). 
Deste modo, podemos entender a solicitação inicial de Maturana, em Biología del fenómeno social, quando afirma que, para podermos cumprir seu propósito de argumentação biológica, nós, leitores, devemos aceitar cinco condições iniciais, sem dar sua completa fundamentação biológica, alegando questão de espaço, mas, em certo modo, podemos decifrar esta ocorrência também com base no conceito de objetividade entre parênteses, no qual, como já referimos, não existe a pretensão da isenção do observador sobre o observado. É como se o observador dissesse sobre o observado: "Eu digo isto e assumo suas consequências com base nas minhas experiências" e, assim fazendo, estabelece que a validade das explicações que aceitamos não se encontra na "qualidade" do objeto em si e, sim, na concordância de nossa interação com o objeto na produção do próprio objeto. A capacidade do observador de conhecer se relaciona com a maneira na qual se explica o fenômeno, ou seja, explicar é sempre uma maneira de propor uma reformulação de nossa experiência que seja plausível para o observador.

Quando escutamos uma proposição explicativa ou uma reformulação da experiência e a aceitamos como explicação, o que aceitamos não é uma referência a algo independente de nós, mas uma reformulação da experiência com elementos da experiência que satisfaça algum critério de coerência que nós mesmos propomos explícita ou implicitamente. Em outras palavras, nós nos damos conta também de que depende de nós aceitarmos ou não uma certa reformulação da experiência a ser explicada como explicação dela, segundo um critério de aceitação que temos em nosso escutar e, portanto, que a validade das explicações que aceitamos se configura em nossa aceitação e não independentemente dela. (MATURANA, 1998, p. 47, grifos do autor).

Estas cinco proposições iniciais, que serão seguidas de suas implicações, são feitas pela configuração de perguntas que, ao serem "respondidas", nos oferecerão a construção de um pensamento mais complexo em fundamentação ao ser humano social/individual com base na biologia do fenômeno social.

A primeira pergunta é: ¿Que es una respuesta aceptable [...]. Como reconocer una respuesta adecuada si uno no sabe de antemano cual es? (MATURANA, 2006, p. 70). Esta questão pode ser considerada uma das preocupações epistemológicas científicas de muitos autores, independentemente da resposta que se dê a ela, pois questiona exatamente o fazer científico entre suas indagações e supostas "respostas". Lembrando que epistemologia significa, em sentido comum, um discurso sobre a filosofia da ciência em seus aspectos lógicos e metodológicos, mas que, ao longo da história, tem manifestado diferentes conotações com base no sentido que se dá ao próprio conceito de ciência, à possibilidade da construção de um saber científico e seus limites (ABBAGNANO, 2007, p. 183). Não é por acaso existirem várias epistemologias - que podem ser, inclusive, opostas entre si - que, em sentido geral, podem ser compreendidas como uma reflexão sobre o conhecimento científico.

Retornando à pergunta inicial de Maturana, que manifesta a sua reflexão epistemológica, as respostas, para serem científicas, devem respeitar algumas condições, como ser a proposição de mecanismos conceituais ou concretos, que, através de seu operar, possam gerar os fenômenos contidos na pergunta. Ou seja, as respostas científicas são geradoras no sentido de que, se o mecanismo realizado na proposição da resposta a uma pergunta não é um sistema 
ou não funciona, deve-se reformular a pergunta. Na questão do que é um sistema social para Maturana, este vai buscar um mecanismo biológico que possa gerar os sistemas que, em seu funcionamento, compreendam todos os fenômenos reconhecidos como sociais.

Es, pues, de esta manera que quiero contestar la pregunta ¿qué es un sistema social?, al proponer lo que yo considero es el mecanismo biológico que genera los sistemas que exhiben en su operar todos los fenómenos que observamos en los sistemas que cotidianamente reconocemos como sistemas sociales. Haré esto en la forma de una definición, y espero que si el sistema que propongo cumple con este requisito, el lector lo acepte como respuesta a dicha pregunta (MATURANA, 2006, p. 70).

A segunda pergunta, ¿qué son los seres vivos?, não se restringe somente aos homens e sim a todos os seres viventes entendidos como sistemas determinados estruturalmente. A palavra "estruturalmente" não pode, neste caso, ser diretamente relacionada ao estruturalismo linguístico iniciado por Saussure ou ao pós-estruturalismo. Maturana, autor complexo, pode ser situado mais especificamente no contexto de autores como o biólogo Ludwig von Bertalanffy ou, posteriormente, Gregory Bateson, autores estes que pensaram mais especificamente em elaborar uma teoria dos sistemas e as possíveis relações entre estes, com a diferença de que Maturana, guardando distância de von Bertalanffy, tenta explicar os seres vivos não através da relação destes com o ambiente, mas através dos processos internos que se realizam dentro do próprio sistema como estrutura fechada: "La tesi è che l'identità del sistema non sia il risultato diretto dell'interazione fra sistema e ambiente, ma un processo interno al sistema stesso, e che quindi il sistema autopoietico vada considerato come un sistema chiuso (CUSINATO, 2009, p. 120) ${ }^{3}$.

Não é o meio a determinar mudanças nos seres vivos, mesmo que estes sejam considerados sistêmicos e dialogantes entre si. As mudanças que em nós ocorrem, sob a forma de mudanças estruturais, são determinadas em nossa estrutura interna, impulsionadas pelas nossas interações com o meio, por meio da homeostase em congruência com este, em um devir de contínua mudança estrutural, que Maturana denomina la coreografía de su danza estructural (MATURANA, 2006, p. 71). É desta dinâmica estrutural de mudanças contínuas de componentes que temos a formulação do conceito fundamental de autopoiesis:

Es esta condición de continua producción de sí mismos, a través de la continua producción y recambio de sus componentes, lo que caracteriza a los seres vivos y lo que se pierde en el fenómeno de la muerte. Es a esta condición a la que me refiero al decir que los seres vivos son sistemas autopoiéticos y que están vivos sólo mientras están en autopoiesis (MATURANA, 2006, p. 71, grifo do autor).

\footnotetext{
${ }^{3}$ A tese é que a identidade do sistema não seja o resultado direto da interação entre o sistema e o ambiente, mas um processo interno ao sistema mesmo e que, deste modo, o sistema autopoiético deve ser considerado um sistema fechado.
} 
$\mathrm{Na}$ terceira pergunta, ¿Cómo es el cambio estructural?, temos a ratificação do que já foi estabelecido na segunda questão (¿qué son los seres vivos?), de modo a instituir que os seres vivos são um destes sistemas em contínua mudança estrutural, como consequência das interações com o meio a partir de uma estrutura inicial.

$\mathrm{Na}$ quarta e na quinta indagações, respectivamente La conservación de la organización e Conservación de la adaptación, temos uma melhor explicação do elemento invariável universal ao qual se refere Maturana:

Los seres vivos participan en los fenómenos en que participan como seres vivos sólo mientras la organización que los define como seres vivos (la autopoiesis) permanece invariante. Esta afirmación apunta a una relación universal: algo permanece, es decir, algo mantiene su identidad, cualesquiera sean sus cambios estructurales, sólo mientras la organización que define su identidad no cambia. [...] Si no se conserva la congruencia estructural entre ser vivo y medio, las interacciones en el medio gatillan en el ser vivo cambios estructurales que lo desintegran y muere. Esta congruencia estructural entre ser vivo y medio (cualquiera que éste sea) se llama adaptación (MATURANA, 2006, p. 72).

Nas mudanças estruturais, dois elementos são invariáveis: a organização e a adaptação. Na preservação da organização, temos a autopoiesis, que pode morrer se, em suas modificações estruturais, não se preserva a organização. Na preservação da adaptação, temos a congruência com o meio que se preserva e, quando isto não ocorre, inicia-se a desintegração estrutural para a morte. É um devir de "[...] cambios estructurales congruentes entre ser vivo y el medio" (MATURANA, 2006, p. 73), onde o autor tenta estabelecer que o ser vivo e o meio se relacionam congruentemente na criação de uma unidade espontânea em mútua produção um do outro, o que ele vai denominar de coderiva ontogénica e filogénica.

Nas cinco condições iniciais, no texto Biología del fenómeno social, constatamos a tentativa de Maturana da compreensão da pergunta ¿qué es un sistema social?, por meio da ação de um sistema biológico universal capaz de promover todos os fenômenos sociais. Mas o que são sistemas sociais e quais as suas implicações, segundo este autor?

Cada vez que los miembros de un conjunto de seres vivos constituyen con su conducta una red de interacciones que opera para ellos como un medio en el que ellos se realizan como seres vivos y en el que ellos, por lo tanto, conservan su organización y adaptación y existen en una coderiva contingente a su participación en dicha red de interacciones, tenemos un sistema social (MATURANA, 2006, p. 73).

A ideia de coderiva é central, ao mesmo tempo que polêmica, pois, se existe algo observável nos sistemas sociais humanos, possível de se questionar, é a capacidade destes de relações contingenciais. Mas, este nosso questionamento, para Maturana, parece não ter sentido, pois a própria definição de sistema social é que esta deriva existe, ou seja, quando esta não se apresenta, não estamos diante de um sistema social: "Así, por ejemplo, un conjunto humano que no incorpora la conservación de la vida de sus miembros como parte de su definición operatoria 
como sistema, no constituye un sistema social” (MATURANA, 2006, p. 74). Isto porque Maturana está sempre preocupado com dois conceitos caros à biologia, que são a conservação e a variação, não como contraposição, e sim como pressupostos que se constituem mutuamente. Deste modo, podemos entender como este autor descreve, ao mesmo tempo, a autopoiesis como a possibilidade da construção de um devir "insurgente", com a afirmação de que os sistemas sociais são constitutivamente conservadores. Mas, qual é o mecanismo fundamental que permite a interação entre os sistemas sociais humanos?

[...] el lenguaje, como característica del ser humano, surge con lo humano en el devenir social que le da origen. [...] En ese operar social primario, sin embargo, no hay objetos para los miembros del sistema social, pues ellos sólo se mueven en la coordinación conductual de la acción que han debido adquirir (aprender) al hacerse miembros de él. En el dominio social humano, y como resultado de las interacciones que tienen lugar entre los miembros de una sociedad humana, hay lenguaje cuando hay recursividad lingüística, es decir, cuando un observador ve como coordinación conductual sobre la coordinación conductual (MATURANA, 2006, p. 73).

A linguagem será central para a compreensão da teoria de Maturana, mas não é a análise da linguagem que encontramos nas estruturas de Saussure ou Chomsky, ou nos atos linguísticos de Wittgenstein, ou, ainda, na psicologia social discursiva que coloca a linguagem como uma ação social construtiva (AMERIO, 2007, p. 251). É na história evolutiva do homem de longa duração, milhões de anos, que Maturana vai construir a ideia da linguagem como coordenação de comportamento primário, que oferece a possibilidade de entender a construção de um mundo de ações e objetos sociais e, também, uma auto-observação, diferenciando o "eu" dos “outros":

De esto resultan, por una parte, la producción de un mundo de acciones y objetos que sólo tienen existencia y significado en el dominio social en que surgen y, por otra, la producción de la auto-observación, que nos lleva a distinguirnos como objetos a nosotros mismos y a nuestras circunstancias, en la reflexión que constituye la autoconciencia como fenómeno que también tiene existencia y sentido sólo en el dominio social (MATURANA, 2006, p. 73).

É na construção desta linguagem que surgiu na história evolutiva dos seres humanos como coordenação de comportamento primário, que pode elaborar suas interações cooperativas e, assim fazendo, promover um sistema social onde se realiza sua autopoiesis. É nesta recorrência de interações cooperativas, em acoplamentos estruturais recíprocos, que Maturana introduz seu conceito biológico de amor, que ele definirá como uma "pegajosidad biológica" sem a qual o ser humano se desintegra.

É nesta concepção de amor que Maturana vai afirmar que "todo sistema social humano se funda en el amor” (MATURANA, 2006, p. 79). Mas, como compreender esta declaração se encontramos, neste mesmo texto, afirmações que dizem que o amor em sua ética de aceitação do outro incondicional pode ser substituído por uma moralidade e por hierarquias de subordinação 
humana? Aqui, devemos realçar que esta concepção de amor não pode ser confundida com descrições filosóficas ou religiosas do amor, pois aqui temos a ideia de um amor biológico que se desenvolveu através da linguagem, na construção das relações sociais cooperativas, dando-nos a particularidade humana onde o individual e o social são biologicamente inseparáveis. Uma vida social que não inclua o individual "eu" e o social "os outros", na abertura de um espaço de coexistência como parte integrante da mesma estrutura biológica, não é, segundo Maturana (2006), a expressão de uma socialização genuína e leva à desintegração dos seres. Contudo, não é também a negação de que as relações sociais de conflito não existam e sim a manifestação de que estas são problemas culturais e que, por isto, podem ser resolvidos - se assim desejarmos.

Maturana (2006), na conclusão deste breve texto, admite que este possa parecer muito difícil a seus leitores e exalta uma de suas convicções teóricas para reforçar a ideia de que, por experiência própria, nós, seus leitores, conhecemos a natureza íntima do fenômeno social que está na aceitação e no respeito ao outro, porque faz parte de nossa estrutura biológica que fundou o social:

Es posible que para muchos lectores este artículo aparezca como difícil. Sin embargo, me parece que de hecho no lo es, pues estoy seguro, que todos los lectores conocen, por su propia experiencia, la naturaleza íntima del fenómeno social, y saben que su fundamento es ético. Es decir, estoy seguro que todos los lectores saben que la naturaleza íntima del fenómeno social humano está en la aceptación y respeto por el otro que está en el centro del amor como fundamento biológico de lo social. Y, por último, estoy seguro que todos los lectores saben que la armonía social no surge de la búsqueda de lo perfecto a que invitan todas las enajenaciones ideológicas, sino de estar dispuesto a reconocer que toda negación, accidental o intencional, particular o institucional, del ser humano como lo central del fenómeno social humano, es un error ético que puede ser corregido sólo si se le quiere corregir (MATURANA, 2006, p. 83).

Independentemente das concordâncias ou das discordâncias que podemos ter com a teoria da Biología do fenómeno social, não podemos deixar de evidenciar o alto potencial educativo que esta nos traz, em um momento de dificuldade de coexistência social humana que, em nome da competição, tem colocado em questão a própria sobrevivência dos seres humanos, em função da utilização dos recursos de nosso planeta como algo privado de algumas corporations e não como patrimônio de todos os seres vivos. É este "potencial educativo", baseado na colaboração como elemento base da biologia do fenômeno social, que pretendemos analisar brevemente em seguida, em outro texto deste autor, dedicado à educação.

\section{A biologia do conhecer na educação}

Em Uma abordagem da educação atual na perspectiva da biologia do conhecimento, inserido no livro Emoções e linguagem na educação e na política, Maturana (1998), em um texto mais acessível, em comparação ao Biología del fenómeno social, inicia seu discurso tentando responder à pergunta 
se a educação atual no Chile serve à sua juventude e, em caso de resposta afirmativa, para que ou para quem. Questão de extrema complexidade e de muitos discursos possíveis, pois a educação e, em consequência, a escolaridade, têm sido alvos de inúmeros discursos em todo o mundo. A chamada "crise da educação" não é mais considerada uma crise, pois a definição de crise é de algo passageiro e o que ocorre na educação hodiernamente é estrutural. Ainda que se possa fazer uma análise sociológica, responsabilizando os novos paradigmas do capitalismo internacional, baseados na globalização e nos meios tecnológicos atuais, como os vilões de uma educação global sempre em maior dificuldade (OLIVEIRA; LIBÂNEO, 1998, p. 599-600), ressaltamos que esta leitura não seja totalmente satisfatória, dada a complexidade do problema que é de longa história e relacionado a uma complexidade maior do que as ideologias socioeconômicas:

A educação, que é complexa por essência, influi e é influenciada pelas partes e aspectos que a define e constitui [...] é urgente repensá-la a partir de uma visão totalizadora que a torne envolvida com as partes e os recortes, mas sempre em função das partes e de um todo uno, múltiplo e complexo, simultaneamente (MORIN, 1990 apud PETRALIA, 1995, p. 16).

Certamente, o contexto atual, global e tecnológico, faz parte da problemática, mas não pode, em nossa compreensão, condicionar um tema a uma única leitura, de base exclusivamente econômica. E é nesta conjuntura que este texto de Maturana (1998) nos proporciona a possibilidade de outra concepção da educação e da escolaridade atuais, que muito contribuem à compreensão complexa de uma problemática igualmente complexa. Maturana (1998) inicia sua reflexão/resposta deslocando o significado da pergunta, de modo a inserir o nosso desejo na mesma e, assim fazendo, coloca-nos a responsabilidade dos afetos e não somente da tarefa educativa a ser cumprida que, entendida exclusivamente como tarefa a ser seguida, não serve a ninguém:

O conceito de servir é um conceito relacional: algo serve para algo em relação a um desejo. Nada serve em si mesmo. No fundo, a pergunta é: $\mathrm{O}$ que queremos da educação? Acho que não se pode considerar nenhuma pergunta sobre os afazeres humanos, no que diz respeito ao seu valor, à sua utilidade ou àquilo que se pode obter deles, se não se explicita o que é que se quer. Perguntarmos se a educação chilena serve, requer respostas a questões como: O que queremos com a educação? O que é educar? Para que queremos educar? E, em última instância, a grande pergunta: Que país queremos? (MATURANA, 1998, p. 11-12, grifo do autor).

Maturana, com o deslocamento da questão da função ao desejo e, posteriormente, falando de educação e nação, tenta utilizar um de seus conceitos na análise desta problemática, ou seja, o conceito de sistemas que se relacionam entre si. A escolaridade como sistema deve (ou deveria) estar em congruência com o sistema do país. Faz, inclusive, alusão a um tempo quando, na sua juventude, os seus desejos educacionais como estudante universitário eram aqueles de devolver ao país o que estava recebendo. Hoje, a situação é diferente, pois a preocupação maior das novas gerações parece ser prioritariamente aquela de preparar-se ao mercado de trabalho 
e de não relacionar os propósitos individuais àqueles sociais, além de serem novas gerações criadas sob a insígnia da competição e não da colaboração. Seguramente, podemos aqui fazer uma crítica a Maturana que, a nosso ver, apesar da ótima leitura das atuais gerações, ideologiza de modo excessivo a sua geração, pois, se ela tivesse sido uma geração inteiramente comprometida com o social, certamente não teríamos o resultado atual. Contudo, a sua contribuição maior, como introdução à pergunta reformulada, qual educação/país desejamos, é aquela de uma concepção educação/país baseada na cooperação, ao invés da competição.

Mas, como fazer esta passagem da competição à cooperação? Maturana, para responder a isto, faz várias considerações sobre o que é o ser humano, o que somos nós, utilizando-se de sua teoria biológica do fenômeno social. Inicia com um discurso sobre a razão e a emoção, afirmando que caracterizar os seres humanos como seres da razão é um antolho que nos impede de enxergar que não existe um fundamento transcendental racional independente do que fazemos como seres vivos, ou seja, sendo a emoção nossa constituição biológica primária, como seres vivos, é ela a criadora de nossa razão e nossas ações no mundo - e não o contrário. É através das emoções que podemos ter uma ação diferente neste mundo. Desta forma, podemos entender a afirmação de que "[...] biologicamente, as emoções são disposições corporais que determinam ou especificam domínios de ações”. (MATURANA, 1998, p. 16).

Maturana (1998), buscando compreender, através da etologia, o desenvolvimento humano ao longo dos milênios, afirma que o desenvolvimento do cérebro humano está relacionado principalmente com a linguagem, no seu entrelaçamento com o emocional e não com a utilização de instrumentos. Afirmação fundamental, pois é por meio dela que podemos compreender o motivo pelo qual, para Maturana, a competição é um fenômeno que se dá no âmbito cultural humano, com base nas racionalidades de instrumento. Diferentemente da colaboração, que seria um fenômeno que se dá no âmbito biológico, com base na emoção e em suas possíveis ações: "[...] quando falamos de emoções, fazemos referência ao domínio de ações em que um animal se move”. (MATURANA, 1998, p. 22).

Para que este processo emotivo tivesse início, Maturana (1998) declara a necessidade de uma emoção fundadora particular sem a qual a convivência linguística entre os homens não teria sido possível. Esta emoção particular é o amor, definido por Maturana (1998, p. 22) como "a emoção que constitui o domínio de ações em que nossas interações com o outro fazem do outro um legítimo outro na convivência". Se isto não tivesse ocorrido, não teria acontecido a história evolutiva social do ser humano, ou seja, é no encontro, no domínio do que Maturana vai chamar de coordenações consensuais de conduta através desta emoção fundadora - o amor -, que temos a possibilidade da convivência social. Maturana vai nos declarar dependentes do amor. Deste amor evolutivamente constituído ocorreram as condições para que as interações recorrentes pudessem estabelecer a recursividade nas coordenações consensuais de conduta que, por sua vez, possibilitaram a linguagem:

Mas, sobretudo no presente momento da história evolutiva a que pertencemos - que começou com a origem da linguagem, quando o estar na linguagem se fez parte do modo de vida que, ao conservar-se, constituiu a linhagem Homo a que pertencemos -, somos animais dependentes do amor. O amor é a emoção central na história evolutiva humana desde o início, e toda ela se dá como uma história em que a conservação de um 
modo de vida no qual o amor, a aceitação do outro como um legítimo outro na convivência, é uma condição necessária para o desenvolvimento físico, comportamental, psíquico, social e espiritual normal da criança, assim como para a conservação da saúde física, comportamental, psíquica, social e espiritual do adulto. Num sentido estrito, nós, seres humanos, nos originamos no amor e somos dependentes dele. Na vida humana, a maior parte do sofrimento vem da negação do amor: nós, seres humanos, somos filhos do amor (MATURANA, 1998, p. 25, grifo do autor).

Mas, por fim, o que é educar? Visto que somos sistemas determinados em nossa estrutura, qual o sentido em educar? Para Maturana (1998), o fato de sermos sistemas determinados em nossa estrutura não é motivo de imobilização, pois é o reconhecimento de que nossa individualidade não reside em nosso corpo que nos dá a condição de "trabalharmos" através da convivência:

Isto é, toda história individual humana é a transformação de uma estrutura inicial hominídea fundadora, de maneira contingente com uma história particular de interações que se dá constitutivamente no espaço humano. Esta se constituiu na história hominídea a que pertencemos com o estabelecimento do linguajar como parte do nosso modo de viver (MATURANA, 1998, p. 28).

Assim, devemos considerar a educação e o educar em função de nossa disposição de desencadearmos mudanças em nossa formação biológica estrutural, sem perder a organização que é uma invariante. Esta concepção de educação e de educar é um processo contínuo e sabemos, por experiência, o quão conservador pode ser, pois, como afirma Maturana (1998, p. 22), "todo sistema é conservador naquilo que é constitutivo, ou se desintegra."

Maturana (1998), por fim, vai tentar nos descrever que, se aceitamos que a emoção fundamental que define o homem é o amor, a coexistência, a cooperação e a acolhida do outro como um legítimo outro na criação de ações e espaços para todos, então, teremos um motivo para educar. Para tanto, necessitaremos educar nossas crianças e nossos adolescentes em direção de um fazer promotor de um conhecer, e à construção de um desejo que tenha relação com o mundo cotidiano.

\section{Consideração pedagógica}

Pudemos observar, nos dois textos considerados, Biología do fenómeno social e Uma abordagem da educação atual na perspectiva da biologia do conhecimento, uma certa complementariedade da proposta teórica de Maturana, pois, no primeiro texto, temos os parâmetros descritivos de uma teoria biológica do social com a análise da origem dos seres humanos, a noção de autopoiesis, a nossa linguagem, o amor como fundamento humano etc. No segundo, o declarado intento de que esta teoria pode ser transformadora do comportamento social humano - em uma questão fundamental como a educação e a escolaridade. Procuramos, em nosso texto, compreender a Teoria biológica do social sem a intenção de um juízo moral de verdadeiro ou falso, e sim, avaliando 
os motivos que levaram Maturana à descrição da mesma em seus axiomas, como, por exemplo, a superação da dicotomia biológico em contraposição ao social.

Uma das considerações de Maturana de maior expressão para a educação e o educar, ao procurar estabelecer as estruturas etológicas dos seres humanos, foi a concepção de que somos constituídos na emoção e não na razão. Esta questão será fundamental para compreendermos a possibilidade de uma educação que não se baseie na razão como promotora da emoção, e sim, precisamente o contrário. Deste modo, nossa função educativa não é estritamente relacionada aos conteúdos educativos/escolares e, sim, tentarmos fazer com que nossos alunos experimentem emoções que estimulem a cooperação, para que tenham maior capacidade de construir um mundo onde "o outro" não seja estigmatizado ou colocado para fora. Certamente, a demanda de como criarmos este desejo permanece um desafio educativo. Contudo, a mudança de perspectiva sobre nossa fundação humana pode muito nos auxiliar a refletir sobre a "crise" educacional contemporânea e o desafio da criação de um espaço de ações e de conhecimentos.

\section{Referências}

ABBAGNANO, N. Dicionário de filosofia. São Paulo: Martins Fontes, 2007.

AMERIO, P. Fondamenti di psicologia sociale. Bolonha: Il Mulino, 2007.

CUSINATO, G. Sistemi personali e sistemi autopoietici. Scienza \& Filosofia, Napoli, n. 2, p. 117-127, 2009, Disponível em: <http://www.scienzaefilosofia.com/wp-content/ uploads/2018/03/res507996_12-CUSINATO.pdf>. Acesso em: 15 jan. 2015.

MATRÍZTICA. Disponível em: <http://matriztica.cl/Matriztica/> . Acesso em: 10 dez. 2015.

MATURANA, H. R. Uma abordagem da educação atual na perspectiva da biologia do conhecimento. In: MATURANA, H. Emoções e linguagem na educação e na política. Belo Horizonte: Ed. UFMG, 1998. p. 11-35.

MATURANA, H. R. Biología del fenómeno social. In: MATURANA, H. R. Desde la biología a la psicología. 4. ed. Santiago: Editorial Universitaria, 2006. p. 69-83.

OLIVEIRA, J. F.; LIBÂNEO, J. C. A educação escolar: sociedade contemporânea. Revista Fragmentos de Cultura, Goiânia, v. 8, n. 3, p. 597-612, 1988.

RABELO, A. Prefácio. In: MATURANA, H. Emoções e linguagem na educação e na política. Belo Horizonte: Ed. UFMG, 1998. p. 7-9.

PETRAGLIA, I. C. Edgar Morin: a educação e a complexidade do ser e do saber. 6. ed. Petrópolis: Vozes, 1995.

Artigo recebido em 06/02/2016. Aceito em 01/02/2018.

Contato: Universidade Federal de Roraima, Departamento de Psicologia, Av. Cap. Ene Garcês, 2413, Aeroporto, Boa Vista, RR, 69310-000, Brasil. 